Paula Lamb Quilião ${ }^{1}$

Anaclaudia Gastal Fassa²

María Clara Restrepo ${ }^{3}$

\section{Processo de implantação de um Centro Regional de Refe- rência em Saúde do Trabalhador no Rio Grande do Sul}

\author{
The process of implanting a Regional Worker's Health Reference \\ Center in the state of Rio Grande do Sul, Brazil
}

1 Programa de Mestrado Profissional em Saúde Pública Baseada em Evidências, Universidade Federal de Pelotas. Pelotas, RS, Brasil.

2 Programa de Pós-Graduação em Epidemiologia, Universidade Federal de Pelotas. Pelotas, RS, Brasil.

3 Programa de Doutorado em Epidemiologia, Universidade Federal de Pelotas. Pelotas, RS, Brasil.

Contato:

Paula Lamb Quilião

E-mail:

plambquiliao@gmail.com

Trabalho baseado na dissertação de mestrado de Paula Lamb Quilião intitulada A Saúde do Trabalhador no município de Alegrete-RS: uma análise de dados secundários, defendida em 2009 na Universidade Federal de Pelotas.

Os autores declaram não haver conflitos de interesses.

\section{Resumo}

O estudo avalia a implantação do Centro de Referência Regional em Saúde do Trabalhador da Região Oeste do estado do Rio Grande do Sul (Cerest Oeste), mediante o diagnóstico do perfil ocupacional e de saúde do trabalhador em Alegrete, e propõe estratégias para viabilizar este processo e subsidiar o seu planejamento. Desenvolveu-se um estudo retrospectivo com base em análise quantitativa de dados secundários de bancos institucionais, referentes ao período de 2000 a 2009, e análise qualitativa por meio de entrevistas semiestruturadas com informantes-chave envolvidos no processo de implantação do Cerest. Evidenciou-se que a principal barreira na implantação foi a falta de articulação entre as diferentes esferas de gestão. Isso dificultou a definição de responsabilidades que dessem conta do caráter regional do Centro e implicou em problemas de infraestrutura e recursos humanos. A definição precoce da equipe e o envolvimento do controle social desde a fase de projeto podem auxiliar no enfrentamento das dificuldades. Faz-se necessário também ampliar as informações epidemiológicas em saúde do trabalhador e facilitar o acesso a elas de forma a instrumentalizar o planejamento das ações do Centro.

Palavras-chave: avaliação de serviços de saúde; políticas de saúde do trabalhador; saúde do trabalhador; vigilância em saúde do trabalhador.

\section{Abstract}

This study assesses the implementing of the Regional Worker's Health Reference Center (Cerest Oeste) by examining the worker's occupational and health profile in Alegrete, a city in the state of Rio Grande do Sul, Brazil. It also proposes strategies to enable this process and subsidize its planning. The authors carried out a retrospective study concerning the period 2000 to 2009 based on quantitative analysis of secondary data from institutional databases, and also qualitative analysis through semi-structured interviews with the key-informers involved in the Cerest implanting process. They observed that the main trouble in implementing the Center was the lack of articulation among the different administrative levels. This led to difficulties in delegating responsibilities that would fit the regional characteristics of the Center and caused infrastructure and human resource problems. To help cope with these difficulties the authors suggest a precocious selection of the staff and the involvement of social control starting in an earlier stage of the project. To subsidize the Center plan of actions it is also necessary to increase and facilitate access to worker's health epidemiological information.

Keywords: health services assessment; occupational health policies; occupational health; workers health surveillance. 


\section{Introdução}

O movimento em prol da saúde do trabalhador no Brasil tem como marco os anos 1970, com ações em defesa do direito ao trabalho digno e saudável. Este movimento permitiu que a saúde do trabalhador fosse discutida e incorporada pela Constituição Federal de 1988. Com a regulamentação da Lei no 8.080/90, ficou definido que cabe ao Sistema Único de Saúde (SUS) atuar na assistência, na vigilância e no controle de agravos à saúde relacionados ao trabalho (HOEFEL; DIAS; SILVA, 2005).

Entre as estratégias para concretizar as ações em saúde do trabalhador, destaca-se a concepção da Rede Nacional de Atenção à Saúde do Trabalhador (Renast) em 2002 (FACCHINI et al., 2005). Sua gestão vem se fortalecendo através dos Centros de Referência em Saúde do Trabalhador (Cerest), que desempenham funções de suporte técnico, educação permanente, coordenação de projetos de assistência, promoção e vigilância à saúde dos trabalhadores. Os Cerests devem estar intimamente articulados com os outros níveis de atenção como parte de uma rede regionalizada, hierarquizada e resolutiva de atenção à saúde.

A Renast faz parte das reformulações pelas quais vem passando a saúde do trabalhador no SUS, que busca superar o campo restrito da Medicina do Trabalho e da Engenharia de Segurança, entendendo a centralidade do trabalho enquanto organizadora da vida social (MENDES; DIAS, 1991; VASCONCELLOS; RIBEIRO, 1997). A Rede propõe que as causas das doenças relacionadas com o trabalho extrapolam a exposição a um grupo de fatores de risco ocupacionais e se contextualiza com fatores socioculturais e econômicos enquanto determinantes do processo saúde-doença. Segundo Facchini (1993), o trabalho determina espaços de dominação e submissão do trabalhador pelo capital e é neste espaço de intenso conflito de interesses que são criadas demandas pela busca de serviços de atenção à saúde do trabalhador.

No Rio Grande do Sul (RS), de acordo com a Portaria GM/MS no 2.437, de 2005 (BRASIL, 2005), que dispõe sobre a ampliação e o fortalecimento da Renast, deveriam ser implantados 12 Cerest e, até 2009, dez foram habilitados. O Cerests Oeste, localizado em Alegrete, município central da Região Oeste do RS, de acordo com o Plano Estadual de Saúde do Trabalhador (RIO GRANDE DO SUL [Estado], 2002), deveria estar em pleno funcionamento desde o primeiro trimestre de 2004, entretanto, em 2009 ainda estava tentando ser habilitado. Apenas o Cerest habilitado pelo Ministério da Saúde, através de Portaria publicada no Diário Oficial da República Federativa do Brasil, recebe o custeio para sua implantação e manutenção do serviço (BRASIL, 2009b).

Este artigo descreve, através de uma avaliação externa do processo de implantação do Cerest Oeste, as barreiras que dificultaram e atrasaram sua implantação, verificando o perfil ocupacional e de saúde dos trabalhadores de Alegrete e apontando como este diagnóstico pode contribuir neste processo. Além disso, este estudo poderá servir como referencial para elaboração de uma metodologia de avaliação do nível de implantação de um Cerest e fornece recomendações mediante análise final dos resultados em relação às suas ações para auxiliar outros Cerests com as mesmas dificuldades.

\section{Métodos}

O presente estudo foi retrospectivo, com análise quantitativa de dados secundários disponibilizados em bancos institucionais de 2000 a 2009, período de construção do diagnóstico, e análise qualitativa, através de entrevistas semiestruturadas realizadas pelo pesquisador responsável com questões abertas a informantes-chave que estavam envolvidos na organização deste Cerest.

Para avaliar o nível de implantação do Cerest Oeste elaborou-se um formulário estruturado baseado na normatização do planejamento da atenção à saúde do trabalhador nas três esferas de governo: o Manual da Renast (BRASIL, 2006a), o Plano Estadual de Saúde do Trabalhador (RIO GRANDE DO SUL [Estado], 2002) e o convênio firmado entre o Município e o Estado para este fim (RIO GRANDE DO SUL [Estado], 2000a). O formulário incluiu itens como infraestrutura, recursos humanos, vigilância em saúde do trabalhador, educação permanente, gestão e planejamento das ações em saúde do trabalhador. Para completá-lo, foram utilizados outros documentos correlatos, como atas do Conselho Municipal de Saúde e entrevistas com informantes-chave da Secretaria Municipal de Saúde, do Conselho Municipal de Saúde e da $10^{\mathrm{a}}$ Coordenadoria Regional de Saúde. O resultado foi analisado pela comparação entre os itens requeridos para implantação do Cerest e aqueles realmente alcançados e/ou executados de acordo com o formulário estruturado.

Um perfil ocupacional do município foi traçado utilizando dados secundários do Instituto Brasileiro de Geografia e Estatística (IBGE) e do Ministério do Trabalho e Emprego (MTE) através do Cadastro Geral de Empregados e Desempregados (Caged). A análise descritiva permitiu estimar o número de trabalhadores e sua distribuição por tipo de ocupação. Os dados de flutuação do emprego possibilitaram observar a tendência do mercado de trabalho em Alegrete de 2003 a 2008 (BRASIL, 2009e). Apenas o Censo/2000 possuía informações sobre Trabalho no município de Alegrete no período da coleta de dados do estudo (INSTITUTO BRASILEIRO DE GEOGRAFIA E ESTATÍSTICA, 2000). 
Para caracterizar aspectos relacionados à saúde do trabalhador, buscaram-se bancos de dados disponíveis sobre acidentes de trabalho, morbidades profissionais e morbidades relacionadas com o trabalho. Neste caso, a principal fonte de informações no Brasil provém do Ministério da Previdência Social/Instituto Nacional do Seguro Social (MPS/INSS) através da Comunicação de Acidente de Trabalho (CAT). Esse registro é utilizado na concessão de benefícios para acidentes ou doenças decorrentes do trabalho e, portanto, estas informações apresentam reconhecida subnotificação e restringem-se aos trabalhadores contribuintes (WÜNSCH FILHO, 2000). Deste modo, ficam excluídos funcionários públicos, autônomos, pequenos comerciantes, trabalhadores domésticos e os informais (WÜNSCH FILHO, 2004; CORREA; ASSUNÇÃO, 2003).

Para este estudo, a Agência do MPS/INSS de Alegrete disponibilizou o banco de dados dos benefícios auxílio-doença por acidentes de trabalho concedidos em 2007. Segundo o Ministério da Previdência Social (BRASIL, 2009a), este benefício constitui no pagamento de renda mensal ao acidentado urbano ou rural que sofreu acidente do trabalho ou doença das condições de trabalho, como está previsto no Art. 59 da Lei $n^{\circ} 8.213$ (BRASIL, 1991). Os dados disponibilizados foram: sexo, faixa etária, diagnóstico conforme Classificação Internacional de Doenças - CID-10 (ORGANIZAÇÃO MUNDIAL DA SAÚDE, 2008), tempo de concessão, faixa salarial, zona de trabalho e filiação ao MPS/INSS. Foi realizada uma análise descritiva com cálculo de proporções, além de análise destas variáveis estratificadas por sexo utilizando o programa Epi Info 6 (DEAM et al., 1994).

Para ampliar a abrangência da análise de acidentes e agravos em saúde do trabalhador, utilizou-se dados do Sistema de Informações em Saúde do Trabalhador - SIST (RIO GRANDE DO SUL [Estado], 2009b), atingindo mesmo aqueles à margem das estatísticas previdenciárias, uma vez que este não apresenta restrição segundo o tipo de vínculo empregatício (FACCHINI et al., 2005). O Relatório Individual de Notificação de Agravos (RINA) é parte desse sistema e desde 2000 foi instituído como instrumento de notificação compulsória de agravos à saúde do trabalhador no RS pelo Decreto Estadual no 40.222 (RIO GRANDE DO SUL [Estado], 2000b). O RINA é notificado pelas Unidades de Referência (Sentinelas) e analisado pelo Centro Estadual de Vigilância em Saúde da Secretaria Estadual de Saúde. De 2002 a 2009, o Serviço Municipal de Fisioterapia foi a Unidade de Referência em Saúde do Trabalhador em Alegrete (Lei Municipal $\mathrm{n}^{\circ}$ 2.981/2000), o qual cedeu seu banco do SIST com dados mais atualizados, no período de julho de 2008 a junho de 2009 (RIO GRANDE DO SUL [Estado], 2009b). As variáveis estudadas foram: sexo, idade, raça, estado civil, escolaridade, relação de trabalho, ocupação de acordo com a Classificação Brasileira de Ocupações - CBO (BRASIL, 2002), tempo na ocupa- ção, ramo de atividade conforme a Classificação Nacional da Atividade Econômica - CNAE (INSTITUTO BRASILEIRO DE GEOGRAFIA E ESTATÍSTICA, 2002), diagnóstico (CID-10), tipo de acometimento (acidente ou doença), circunstância que gerou o agravo. Foi realizada uma análise descritiva com cálculo de proporções para variáveis qualitativas e de medidas de tendência central e de dispersão para variáveis quantitativas, além de análise das variáveis ocupacionais e de saúde estratificadas por sexo e faixa etária utilizando o programa Stata 10 (STATACORP, 2005).

Além disso, tendo em conta que nem todos os trabalhadores frequentam o sistema de saúde pública, identificaram-se os serviços privados de saúde ocupacional. Através de entrevistas semiestruturadas, foram avaliados a fim de identificar lacunas na notificação dos agravos à saúde do trabalhador do município por parte dos sistemas de informação em saúde, no sentido de que este seja o mais abrangente possível.

Assegurando o comprometimento com as normas éticas, o projeto foi aprovado pelo Comitê de Ética em Pesquisa da Universidade Federal de Pelotas, conforme Ofício nº 062/09 do CEP/UFPEL.

\section{Resultados}

O Quadro 1 apresenta uma linha do tempo do processo de implantação do Cerest Oeste a partir do formulário estruturado preenchido de acordo com as metas alcançadas, se foram totalmente ou parcialmente atingidas e o ano em que ocorreram.

Conforme o Plano Estadual (RIO GRANDE DO SUL [Estado], 2002), o Cerest Oeste iniciou seu processo de implantação em 2000, através do convênio com o Estado para construção do prédio, aquisição de automóvel e de equipamentos. Entretanto, houve um impasse na construção, com atraso na confecção da planta e na localização do prédio. Assim, embora o Centro devesse estar funcionando desde março de 2004, a obra iniciou somente em 2006 e foi concluída em 2007. Foram enviados equipamentos de reabilitação em outubro de 2002 e até o ano de 2009 estavam em posse da 10ª CRS. No Plano Municipal de Saúde de Alegrete para o exercício de 2006, além da construção do prédio, estava prevista a constituição da equipe do Cerest, incluindo 16 profissionais, 10 de nível superior e 6 de nível médio. Desde a fase inicial, em 2000, a equipe era constituída por um médico ortopedista (coordenador do programa), um médico neurologista, um psicólogo e quatro fisioterapeutas lotados na unidade de referência até o Cerest ser habilitado. Entretanto, a equipe progressivamente foi sendo desfeita, com a transferência para outras unidades de saúde. A Secretaria Municipal de Saúde alegou que a manutenção dos recursos humanos do Cerest, tendo em vista seu caráter regional, dependia de repasse estadual de verbas para este fim. 
Quadro 1 Síntese cronológica do processo de implantação do Cerest Oeste, Alegrete, RS, Brasil, 2000 a 2009

\begin{tabular}{|c|l|}
\hline 2000 & $\begin{array}{l}\text { Convênio com Estado - Alegrete: sede do Cerest } \\
\text { Unidade de Referência: Serviço Municipal de Fisioterapia }\end{array}$ \\
\hline 2002 & $\begin{array}{l}\text { Envio de equipamentos para a 10 } \text { a Coordenadoria Regional de Saúde } \\
\text { Coleta do RINA, FIS pela Unidade de Referência }\end{array}$ \\
\hline 2004 & $\begin{array}{l}\text { Coleta de Relatório de Notificação de Acidentes e Violências (Hospital) } \\
\text { Formação do Conselho Gestor (Regimento em 2005) }\end{array}$ \\
\hline 2005 & $\begin{array}{l}\text { SIST deixou de ser notificado (Unidade de Referência e Hospital) } \\
\text { Conferências em Saúde do Trabalhador (controle social) }\end{array}$ \\
\hline 2007 & Término da construção do prédio (previsto para 2004) \\
\hline 2008 & $\begin{array}{l}\text { Retorno da coleta do RINA } \\
\text { Participação em capacitações e reuniões }\end{array}$ \\
\hline 2009 & Elaboração do Projeto de Habilitação (Ministério da Saúde) \\
\hline
\end{tabular}

Cerest: Centro de Referência em Saúde do Trabalhador RINA: Relatório Individual de Notificação de Agravos FIS: Ficha Individual de Notificação de Suspeita de Agravo SIST: Sistema de Informações em Saúde do Trabalhador

A alimentação do SIST contava com um hospital-sentinela, Hospital Santa Casa de Caridade de Alegrete, para notificação de acidentes e violências através do Relatório Individual de Notificação de Acidentes e Violências, cuja coleta ocorreu apenas no período de 2004 a 2005. A falta de supervisão estadual e a pouca cobrança através de pactuação de indicadores em saúde do trabalhador deixaram os responsáveis pela coleta do Relatório Individual de Notificação de Acidentes e Violências à vontade para desistir de alimentar o sistema. O RINA foi coletado regularmente de 2002 a 2005 pela unidade de referência. Com a desagregação da equipe, a notificação do RINA foi praticamente esquecida, com situação regularizada em 2008, quando a notificação passou a ser feita através do sistema de notificação on line ${ }^{4}$. A partir de 2002, iniciou-se uma campanha por parte da Secretaria Estadual de Saúde/RS para efetivar a notificação, cobrando das Unidades de Referência indicadores baseados na notificação em saúde do trabalhador (RIO GRANDE DO SUL [Estado], 2008).

A Comissão Intersetorial em Saúde do Trabalhador não chegou a ser criada. O Conselho Gestor foi criado pelo Conselho Municipal de Saúde em setembro de 2004, teve seu regimento elaborado em janeiro de 2005, mas não apresentou atuação relevante. De acordo com o Conselho Municipal de Saúde, faltou ao Conselho Gestor apoio financeiro para que a representação regional pudesse se deslocar às reuniões. O controle social foi representado em todas as Conferências em Saúde do Trabalhador do ano de 2005 por conselheiros de saúde.

Desde 2008, o processo de implantação do Cerest foi retomado, culminando na elaboração do Projeto de Habilitação para ser submetido ao Ministério da Saúde em 2009.

Alegrete, em 2007, possuía 78.188 habitantes, a terceira maior população entre os municípios da região, de acordo com informações do IBGE (INSTITUTO BRASILEIRO DE GEOGRAFIA E ESTATÍSTICA, 2007).

Ao se traçar um perfil ocupacional deste município, observou-se, segundo os dados do IBGE (INSTITUTO BRASILEIRO DE GEOGRAFIA E ESTATÍSTICA, 2000), que, em 2000, a população economicamente ativa - pessoas de 10 anos de idade ou mais - foi de 39.391 habitantes, em torno da metade da população total do referido ano. A população economicamente ativa ocupada - pessoas com 10 anos de idade ou mais ocupadas na semana de referência - foi de 32.358 indivíduos, dos quais $63 \%$ eram homens. Conforme os dados do IBGE para a População Economicamente Ativa Ocupada quanto a posição na ocupação, $68 \%$ eram empregados, $24 \%$ eram trabalhadores por conta própria, $4 \%$ eram empregadores, $3 \%$ eram não remunerados

${ }^{4}$ www.sist.saude.rs.gov.br 
em ajuda a membro do domicílio e $1 \%$ era de trabalhadores na produção para o próprio consumo. Entre os empregados, $48 \%$ tinham carteira de trabalho assinada, 33\% não tinham carteira de trabalho assinada e 19\% eram militares e funcionários públicos estatutários. De acordo com o Censo do IBGE (INSTITUTO BRASILEIRO DE GEOGRAFIA E ESTATÍSTICA, 2000), último a coletar dados sobre mercado de trabalho em Alegrete, observou-se que os cinco grandes grupos de ocupação (CBO) com maior número de trabalhadores no município foram os trabalhadores dos serviços e vendedores do comércio em lojas e mercados (33\%), seguidos dos trabalhadores da produção de bens e serviços industriais (18\%), agropecuários, florestais, de caça e pesca (16\%), serviços administrativos (7\%) e forças armadas, policiais e bombeiros militares (6\%).

Para avaliar a tendência do mercado de trabalho no município, utilizaram-se informações geradas pelo Caged referentes à flutuação de emprego no período de 2003 a 2008. Na análise sobre os setores produtivos que mais admitiram, a agropecuária e a indústria de alimentação mostraram grande número de empregos abertos no período. Entretanto, a indústria de alimentação apresentou queda no ano de 2007 devido à escassez de gado para o abate nos frigoríficos gaúchos (FEDERAÇÃO DAS ASSOCIAÇÕES COMERCIAIS E DE SERVIÇOS DO RIO GRANDE DO SUL, 2007).

A última análise foi a elaboração do perfil de saúde do trabalhador em Alegrete. Conforme informações disponibilizadas pela Agência local do INSS, dos 139 benefícios emitidos em 2007 por acidente de trabalho, 135 deles tiveram um tempo de concessão menor que 30 dias, 138 eram referentes a trabalhadores urbanos e 79,1\% eram homens.

A maioria dos benefícios foi relacionada a acidentes do trabalho (50\%) relacionados a lesões, envenenamentos e outras causas externas e traumatismos envolvendo múltiplas regiões do corpo, 35\% a doenças do sistema osteomuscular e tecido conjuntivo, $2 \%$ a outros diagnósticos e $12 \%$ a diagnósticos não definidos.

No sexo masculino, os diagnósticos mais frequentes foram dor lombar $(7,3 \%)$, dorsalgia $(4,5 \%)$ e cervicalgia $(3,6 \%)$. Em relação à distribuição por faixa etária, $31 \%$ tinham entre 30 a 39 anos, $26,4 \%$ entre 40 a 49 anos, $24,5 \%$ entre 20 a 29 anos. Quanto à renda, 61,8\% recebiam um salário-mínimo e apenas um indivíduo recebia salário entre sete a oito salários-mínimos.

No sexo feminino, $17,2 \%$ dos diagnósticos foram sinovites e tenossinovites, enquanto cervicalgia teve $6,9 \%$ dos diagnósticos. As faixas etárias entre 40 e 49 anos e entre 30 e 39 anos concentravam, cada uma, $38 \%$ dos trabalhadores em benefício acidentário, enquanto a faixa entre 20 e 29 anos, $24 \%$. Quanto à renda, 58,6\% das mulheres recebiam um salário-mínimo, sendo que as que recebiam maior salário ganhavam entre quatro a cinco salários-mínimos.

A Tabela 1 apresenta os resultados da análise dos RINA coletados no período de julho de 2008 a junho de 2009 pela unidade de referência em saúde do trabalhador. Dos 77 trabalhadores notificados, $65 \%$ eram do sexo masculino, $52 \%$ tinham escolaridade em nível fundamental incompleto. A idade média foi de 42,2 anos (DP \pm 9,8 anos), com maior número de acometidos acima dos 30 anos de idade. Grande parte dos trabalhadores era da zona urbana $(75,3 \%)$ e $58,4 \%$ tinham carteira assinada. Quanto à ocupação, categorizada por grandes grupos de CBO, 35\% trabalhavam no setor industrial, com predomínio dos trabalhadores da construção civil (ajudante de obras) e da indústria de alimentação (magarefe).

Observando a morbidade, verificou-se que 54,5\% dos diagnósticos eram devidos a lesões, envenenamentos e outras causas externas e $45,5 \%$ devidos a doenças do sistema osteomuscular e tecido conjuntivo, sendo que a síndrome do supraespinhoso/ manguito rotador foi o diagnóstico mais frequente. A situação geradora do agravo, em sua maioria, foi decorrente de quedas ou de exposição a fatores ambientais artificiais, tais como impacto com objetos ou esmagamento.

Na análise das informações derivadas do RINA, observou-se uma associação significativa entre o tipo de diagnóstico e o sexo dos trabalhadores. O principal diagnóstico de agravo no sexo masculino foi devido a traumatismos, envenenamentos e outras causas externas, enquanto o principal diagnóstico no sexo feminino foi devido a doenças do sistema osteomuscular (Tabela 2).

Entre os serviços privados de saúde de Alegrete, notou-se que grande parte dos planos de saúde servia ao setor bancário. Existia um plano de saúde específico para os funcionários públicos estaduais e municipais (Alegrete), um para os militares e um para os bombeiros e brigada militar. Outros dois serviços privados de saúde ocupacional mantinham convênio com empresas de setores variados. Empresas do setor da indústria de alimentação possuíam serviços de saúde ocupacional e planos de saúde próprios. Entretanto, dos 12 serviços de saúde entrevistados, apenas 6 apresentaram tratamento fisioterápico para os conveniados, abrangendo apenas a categoria dos bancários. 
Tabela 1 Caracterização dos casos notificados por RINA* pela Unidade de Referência em Saúde do Trabalhador. Alegrete, RS, Brasil, julho de 2008 a junho de 2009

\begin{tabular}{|c|c|c|}
\hline Variável & $N(n=77)$ & $\%$ \\
\hline \multicolumn{3}{|l|}{ Sexo } \\
\hline Masculino & 50 & 64,9 \\
\hline Feminino & 27 & 35,1 \\
\hline \multicolumn{3}{|l|}{ Idade (em anos completos) } \\
\hline$<30$ & 10 & 13,0 \\
\hline $30-39$ & 20 & 26,0 \\
\hline $40-49$ & 27 & 35,1 \\
\hline 50 ou mais & 20 & 26,0 \\
\hline \multicolumn{3}{|l|}{ Escolaridade } \\
\hline Não alfabetizado & 1 & 1,3 \\
\hline Fundamental incompleto & 40 & 52,0 \\
\hline Fundamental completo & 8 & 10,4 \\
\hline Médio incompleto & 8 & 10,4 \\
\hline Médio completo & 10 & 13,0 \\
\hline Superior incompleto & 4 & 5,2 \\
\hline Superior completo & 6 & 7,8 \\
\hline \multicolumn{3}{|l|}{ Ocupação (por grandes grupos de CBO****) } \\
\hline Bens e serviços industriais (inclusive construção civil) & 27 & 35 \\
\hline Comércio e serviços & 21 & 27,3 \\
\hline Agropecuária & 15 & 19,5 \\
\hline Profissionais das ciências e artes & 4 & 5,2 \\
\hline Técnicos de nível médio & 4 & 5,2 \\
\hline Forças armadas & 4 & 5,2 \\
\hline Poder público e dirigentes & 1 & 1,3 \\
\hline Serviços administrativos & 1 & 1,3 \\
\hline \multicolumn{3}{|l|}{ Área de trabalho } \\
\hline Urbana & 58 & 75,3 \\
\hline Rural & 19 & 24,7 \\
\hline \multicolumn{3}{|l|}{ Relação de trabalho } \\
\hline Assalariado em CLT & 45 & 58,4 \\
\hline Autônomo & 12 & 15,6 \\
\hline Trabalhador informal & 11 & 14,3 \\
\hline Funcionário público & 8 & 10,4 \\
\hline Empregador & 1 & 1,3 \\
\hline \multicolumn{3}{|l|}{ Diagnóstico do agravo (grupo de CID*****) } \\
\hline Lesões, envenenamentos e outras causas externas & 42 & 54,5 \\
\hline Doenças do sistema osteomuscular e tecido conjuntivo & 35 & 45,5 \\
\hline \multicolumn{3}{|l|}{ Situação geradora do agravo (grupo de agentes) } \\
\hline Quedas ou exposição a fatores ambientais artificiais & 37 & 48,1 \\
\hline Condições relacionadas ao trabalho e ao modo de vida & 21 & 27,3 \\
\hline Exposição a substâncias biológicas ou eventos naturais & 12 & 15,6 \\
\hline Acidentes de transporte & 7 & 9,1 \\
\hline
\end{tabular}

* RINA: Relatório Individual de Notificação de Agravos

***: CBO: Classificação Brasileira de Ocupações

CID: Classificação Internacional de Doenças 
Tabela 2 Associação* entre grupo de diagnóstico (CID**) e sexo dos 77 casos notificados por RINA*** pela Unidade de Referência em Saúde do Trabalhador. Alegrete, Brasil, julho de 2008 a junho de 2009

\begin{tabular}{|c|c|c|c|}
\hline Diagnóstico & Masculino & Feminino & Total \\
\hline Doenças do sistema osteomuscular & $14(28 \%)$ & $21(77,8 \%)$ & $35(45,45 \%)$ \\
\hline Lesões, envenenamentos e outras causas externas & $36(72 \%)$ & $6(22,2 \%)$ & $42(54,55 \%)$ \\
\hline Total & $50(100 \%)$ & $27(100 \%)$ & $77(100 \%)$ \\
\hline
\end{tabular}

\section{Discussão}

O Cerest Oeste apresentou processo lento de implantação, visto que muitas das metas não foram completamente alcançadas ou foram alcançadas após o previsto em cronograma dos planos estadual e municipal de saúde, impossibilitando o seu funcionamento adequado. As principais dificuldades foram a falta de articulação entre os gestores das diferentes esferas governamentais e o entendimento aprofundado do Conselho Municipal de Saúde sobre o programa. A Portaria MS no 2.728, de 11 de novembro de 2009 (BRASIL, 2009d), confirma a responsabilidade de cada esfera governamental, cabendo: ao município a execução das ações de referência técnica em âmbitos local e regional; ao Estado, a organização dos Cerest; e à União, a gestão nacional da Renast. Entretanto, ela não define claramente pontos estruturais e operacionais como a manutenção da infraestrutura e a formação de uma equipe profissional.

Em relação à infraestrutura, alguns Centros não receberam financiamento estadual para a construção do prédio ou, no caso de Alegrete que recebeu este recurso, ocorreram desencontros entre o estado e o município (RIO GRANDE DO SUL [Estado], 2009a). Atrasos na confecção da planta e desvalorização monetária do repasse adiaram a construção da obra em três anos. Dúvidas na prestação de contas entre o município e o estado geraram indefinição quanto à situação de propriedade do prédio construído.

Neste Cerest, a formação da equipe técnica foi informal e com dedicação parcial à saúde do trabalhador, insuficiente para as necessidades do Cerest. Sem uma verba própria para contratação de recursos humanos, a exigência de uma equipe mínima de 10 profissionais para Centros Regionais (BRASIL, 2006b) tornou-se impraticável, gerando uma sobrecarga aos orçamentos municipais em cidades longínquas como Alegrete, que apresenta um déficit de profissionais especializados em sua rede de saúde. No estado, em vista deste problema, foi criada a Por- taria $\mathrm{n}^{\circ}$ 70, de 18 de dezembro de 2003 (RIO GRANDE DO SUL [Estado], 2004), da Secretaria Estadual de Saúde, que estabelece um repasse do Fundo Estadual para os Cerests para dar suporte ao pagamento da equipe. Porém, até o ano de 2010, esta portaria estadual não havia sofrido uma reformulação, não garantindo o repasse para os Centros que ainda não foram habilitados. A carência de recursos humanos e a falta de apoio para o custeio da equipe tem sido um dos pontos deficitários em vários Cerests no estado (RIO GRANDE DO SUL [Estado], 2009a). No Brasil, em avaliação da Renast em 2009, foi revelado que a maioria dos Cerest possui pessoal compatível (71,5\%) com os parâmetros definidos como equipe mínima, entretanto, os Cerests regionais têm maior dificuldade para manter uma equipe de servidores públicos estáveis, entre outros pontos preocupantes apontados, como a falta de qualificação dos profissionais (MACHADO; SANTANA, 2011).

Desde o início do processo de implantação, o Cerest Oeste teve como meta realizar notificação pelo SIST como forma de apoiar as atividades de planejamento e vigilância. Entretanto, a coleta acontece apenas na Unidade de Referência. Além do SIST, outros sistemas de informação devem ser alimentados e servem de auxílio no monitoramento da morbimortalidade ocupacional, como o Sistema de Informações sobre Mortalidade, buscando o esclarecimento dos acidentes fatais e que já está sendo feito por Cerests habilitados, e o Sistema de Informação Nacional de Agravos de Notificação (Sinan), através da notificação de 11 agravos relacionados com o trabalho (BRASIL, 2004).

Outro impasse constatado foi o apoio limitado do Conselho Municipal de Saúde à abertura do Cerest Oeste. Outros Cerests já implantados enfrentam dificuldades na participação do controle social em suas atividades (MACHADO; SANTANA, 2011). O Conselho esperava que o Estado alocasse recursos para manutenção do programa, portanto, como órgão fiscalizador, quer evitar que o município seja sobrecarregado pelas demandas regionais sem a devida 
contrapartida financeira e teme que as dificuldades nas negociações do financiamento do Cerest possam causar implantação deficiente, interrupções na prestação do serviço ou fechamento do Centro.

Pode-se constatar que a resistência, papel do controle social, está enfraquecida, uma vez que não existem a Comissão Intersetorial em Saúde do Trabalhador e o Conselho Municipal de Saúde, mesmo em tempos de Pacto pela Saúde, que reconhece o papel do controle social no efetivo monitoramento das ações da gestão. Segundo a Portaria GM no 2.669, de 3 de novembro de 2009 (BRASIL, 2009c), uma das prioridades do Pacto pela Saúde, no biênio 20102011 é a Saúde do Trabalhador. Entretanto, no caso do Cerest Oeste, o pacto pela saúde ainda não viabilizou a pactuação entre gestores.

As análises disponibilizadas através dos bancos fornecidos pela Agência do INSS não continham nenhum dado ocupacional e 12\% dos diagnósticos eram não definidos. Observou-se somente um registro de benefício relativo a trabalhador de zona rural, porém deveria se esperar um maior número de casos pelo potencial agropecuário da região. Uma das metas da Renast é construir uma relação intersetorial entre a saúde e a previdência visando articular e conduzir a padronização dos bancos de dados (FACCHINI et al., 2005). A Política Nacional de Segurança e Saúde no Trabalho conta com esta integração e tem como objetivo principal a promoção e a melhoria da qualidade de vida do trabalhador, implementada por meio de articulação continuada pelos Ministérios do Trabalho e Emprego, da Previdência Social e da Saúde (BRASIL, 2011).

Os serviços privados de saúde que apresentam tratamento fisioterápico para os conveniados abrangem por completo apenas a categoria dos bancários, deixando descoberta parte dos comerciários e totalmente os empregados em indústrias da alimentação e funcionários públicos (municipais e estaduais). Esses profissionais, somados aos trabalhadores domésticos, rurais e informais, caso busquem tratamento fisioterápico no SUS, serão atendidos pelo Serviço Municipal de Fisioterapia. Sendo assim, como Unidade de Referência, os bancários e parte dos comerciários não estariam sendo notificados pelos sistemas de informação em saúde do trabalhador, SIST e Sinan.

Desde 2008, o governo federal tem estimulado a habilitação e a criação de novos Cerests ampliando e fortalecendo a Renast (BRASIL, 2009b). Segundo dados do Ministério da Saúde, até 2007 apenas 110 dos 200 centros a serem abertos foram habilitados e os que já foram habilitados apresentam pontos deficientes (LEÃO; VASCONCELLOS, 2011). Observa-se que um ponto crítico dos Centros Regionais é a dificulda- de da gestão municipal contar com o apoio do governo estadual e envolver os outros municípios da área de abrangência na implantação dos Centros, visto que estes se sentem destituídos de qualquer responsabilidade. Deve existir uma articulação entre os sistemas municipais e o fortalecimento da função reguladora das secretarias estaduais para assegurar a organização das redes assistenciais regionalizadas e que sejam resolutivas na atenção à saúde (SOUZA, 2001).

Estudos como este permitem identificar as fragilidades existentes para superá-las, contribuindo para a efetivação da política proposta. Além disso, seria interessante avaliar os processos de implantação dos centros já habilitados examinando como foram superadas as dificuldades que estão sendo identificadas. Desde 2009, a Renast vem sendo avaliada através de um Inventário de Saúde do Trabalhador. Esse processo de avaliação deve ser aprofundado e integrado ao SUS, em todas as unidades federadas, e deve ser complementado com outras abordagens, buscando um aperfeiçoamento contínuo da Renast.

\section{Conclusão}

Este estudo apontou que a principal dificuldade na implantação foi a falta de articulação entre as diferentes esferas de gestão no sentido de definir responsabilidades que dessem conta do caráter regional do Centro. As dificuldades político-administrativas perpetuam o atraso no processo de implantação, agravada pelo controle social deficitário.

Ao avaliar o perfil ocupacional e de saúde do trabalhador no município, observaram-se falhas na cobertura de alguns setores de trabalho, em especial dos trabalhadores rurais, fundamentais para o mercado de trabalho desta cidade.

Gestores, profissionais da saúde envolvidos e o controle social precisam de um conhecimento aprofundado acerca da Renast e devem trabalhar de forma articulada para viabilizar a implantação e o pleno funcionamento dos Centros. O controle social deve participar ativamente desde a decisão do gestor municipal de implantar o Cerest até o desenvolvimento do plano de ação. Para que exista um processo qualificado de planejamento, baseado na descentralização e na regionalização, os municípios, apoiados pelo Estado e União e junto com o controle social, devem se empenhar para que ele seja organizado levando em conta as características regionais (BRASIL, 2006b).

A atuação do governo federal é de fundamental importância para acelerar a articulação intersetorial entre saúde e previdência, agilizando a padronização dos bancos de dados em saúde do trabalhador, bem como a sua utilização pública, como já acon- 
tece com outras bases de dados do setor saúde. Esta abertura propicia a realização de pesquisas que podem orientar as ações prioritárias em saúde do trabalhador. O SIST em Alegrete ainda precisa melhorar a cobertura de seu banco de dados principalmente através da ampliação das unidades de coleta e inserindo a notificação do Sinan.

Constata-se, então, a importância da avaliação de serviços de saúde, neste caso, no campo da saúde do trabalhador para evitar que outros Cerests passem pelas mesmas dificuldades no seu processo de implantação. A Renast ainda sofre com dificuldades na implantação dos Cerests, e por esta razão faz-se necessária a realização de avaliações pontuais que diagnostiquem e orientem sua implementação (HOEFEL; DIAS; SILVA, 2005). Confor- me o Plano de Ação Mundial sobre a Saúde dos Trabalhadores para o período de 2008 a 2017, a Organização Mundial de Saúde (2007) considera importante realizar medidas que visem melhorar o funcionamento dos serviços de saúde ocupacional e o acesso a eles. Este é o desafio imposto à Renast: ampliar e fortalecer os serviços de saúde do trabalhador com qualidade.

\section{Nota Final}

O Cerest Oeste, em dezembro de 2010, foi habilitado pelo Ministério da Saúde. Este estudo subsidiou o Projeto de Habilitação (2009) e orientou o planejamento e as ações iniciais após sua abertura em 2011.

\section{Contribuições de autoria}

Quilião, P. L.: contribuição substancial no projeto; obtenção, análise e interpretação dos dados e redação do artigo. Fassa, A. G.: contribuição substancial no projeto; análise e interpretação dos dados e redação do artigo. Restrepo, M. C.: contribuição substancial na análise e interpretação dos dados e na revisão crítica do artigo. Todas as autoras aprovaram a versão final do artigo.

\section{Referências}

BRASIL. Decreto nº 7.602, de 07 de novembro de 2011. Dispõe sobre a Política Nacional de Segurança e Saúde no Trabalho - PNSST. Diário Oficial [da] República Federativa do Brasil, Brasília, DF, 08 nov. 2011. Seção 1, p. 9-10.

Lei no 8.213 , de 24 de julho de 1991. Dispõe sobre os Planos de Benefícios da Previdência Social e dá outras providências. Diário Oficial [da] República Federativa do Brasil, Brasília, DF, 25 jul. 1991. Seção 1, p. $14809-14819$.

Ministério da Previdência Social. Boletim Estatístico da Previdência Sócial, v. 14, n. 3, p. 2, 2009a. Disponível em: <http://www.mpas.gov.br/ conteudoDinamico.php?id=482>. Acesso em: 23 mar. 2010.

Ministério da Saúde. Ações e Programas do SUS: distribuição dos CEREST estaduais e regionais por unidades federativas. Disponível em: < http:// portal.saude.gov.br/portal/saude/visualizar_texto. cfm?idtxt=29723\&janela=1 > . Acesso em: $27 \mathrm{dez}$. 2009b.

. Manual de gestão e gerenciamento da Rede Nacional de Atenção Integral à Saúde do Trabalhador. Brasília, DF, 2006a. Disponível em: <http://portal. saude.gov.br/portal/arquivos/pdf/ManualRenast07.pdf $>$. Acesso em: 13 jan. 2009.

. Portaria $\mathrm{n}^{\mathrm{o}} 777$, de 28 de abril de 2004. Dispõe sobre os procedimentos técnicos para a notificação compulsória de agravos à saúde do trabalhador em rede de serviços sentinela específica, no SUS. Diário Oficial [da] República Federativa do Brasil, Brasília, DF, 29 abr. 2004. Seção1, p. 37-38.

. Portaria n⿳0 2.437, de 7 de dezembro de 2005. Dispõe sobre a ampliação e o fortalecimento da Rede Nacional de Atenção Integral à Saúde do Trabalhador RENAST no Sistema Único de Saúde - SUS e dá outras providências. Diário Oficial [da]República Federativa do Brasil, Brasília, DF, 09 dez. 2005. Seção 1, p. 78-80.

. Portaria n⿳o 399 de 22 de fevereiro de 2006b. Divulga o Pacto pela Saúde. Diário Oficial [da] República Federativa do Brasil, Brasília, DF, 23 fev. 2006. Seção 1, p. 43-51.

. Portaria $n^{\circ} 2.669$, de 3 de novembro de 2009. Estabelece as prioridades, objetivos, metas e indicadores de monitoramento e avaliação do Pacto pela Saúde, nos componentes pela Vida e de Gestão, e as orientações, prazos e diretrizes do seu processo de pactuação para o biênio 2010 - 2011. Diário Oficial [da] República Federativa do Brasil, Brasília, DF, 06 nov. 2009c. Seção 1, p. 58-60.

. Portaria $\mathrm{n}^{\mathrm{o}}$ 2.728, de 11 de novembro de 2009. Dispõe sobre a Rede Nacional de Atenção Integral à Saúde do Trabalhador (RENAST) e dá outras providências. Diário Oficial [da] República Federativa do Brasil, Brasília, DF, 12 nov. 2009d. Seção 1, p. 76-77. 
BRASIL. Ministério do Trabalho e Emprego. Cadastro Geral de Empregos e Desempregos. ISPER - dados por município. Disponível em: < http://bi.mte.gov.br/ bgcaged/caged_perfil_municipio/index.php $>$. Acesso em: 20 maio 2009e.

. Portaria $\mathrm{n}^{\mathrm{o}}$ 397, de 9 de outubro de 2002. Aprova a Classificação Brasileira de Ocupações - CBO/2002, para uso em todo território nacional e autoriza a sua publicação. Diário Oficial [da] República Federativa do Brasil, Brasília, DF, 10 out. 2002. Seção 1, p. 74-75.

CORREA, P. R. L.; ASSUNÇÃO, A. A. A Subnotificação de mortes por acidente de trabalho: estudo de três bancos de dados. Epidemiologia e Serviços de Saúde, Brasília, DF, v. 12, n. 4, p. 203-212, 2003.

DEAM, A. G. et al. Epi Info 6 Version 6.04. A word processing, database and statistics program for epidemiology on microcomputers. Atlanta, GA: Center for Disease Control and Prevention, 1994.

FACCHINI, L. A. Uma contribuição da epidemiologia: o modelo da determinação social aplicado à saúde do trabalhador. In: ROCHA, L. E. et al. Isto é trabalho de gente? Vida, doença e trabalho no Brasil. Petrópolis: Vozes, 1993. p. 178-186.

FACCHINI, L. A. et al. Sistema de Informação em Saúde do Trabalhador: desafios e perspectivas para o SUS. Ciência \& Saúde Coletiva, Rio de Janeiro, v. 10, n. 4, p. 857-867, 2005.

FEDERAÇÃO DAS ASSOCIAÇÕES COMERCIAIS E DE SERVIÇOS DO RIO GRANDE DO SUL (FEDERASUL). Frigorífico gaúcho já demite por falta de boi. 2007. Disponível em: <http://www.federasul.com.br/ noticias >. Acesso em: 2 fev. 2009.

HOEFEL, M. G.; DIAS, E. C.; SILVA, J. M. A atenção à saúde do trabalhador no SUS: a proposta de constituição da Renast. In: CONFERENCIA NACIONAL DE SAÚDE DO TRABALHADOR, 3., 2005, Brasília (3. CNST). Coletânea de textos... Brasília: Ministério da Saúde, 2005. p. 72-78.

INSTITUTO BRASILEIRO DE GEOGRAFIA E ESTATÍSTICA. Censo de 2000. Disponível em: <http:// www.ibge.gov.br/home/estatistica/populacao/censo2000/ default.shtm>. Acesso em: 6 jan. 2009.

. Classificação Nacional de Atividades Econômicas - CNAE FISCAL 1.1. Resolução IBGE/ CONCLA n⿳ำ 07, de 16 de dezembro de 2002.

. Contagem da População 2007. Disponível em: <http://www.ibge.gov.br/home/estatistica/populacao/ contagem2007/default.shtm>. Acesso em: 5 dez. 2009.

LEAO, L. H. C.; VASCONCELLOS, L. C. F. Rede Nacional de Atenção Integral à Saúde do Trabalhador (RENAST): reflexões sobre a estrutura de rede. Epidemiologia e Serviços de Saúde, Brasília, v. 20, n. 1, p. 85-100, 2011.

MACHADO, J. M. H; SANTANA, V. (Org.). Inventário de Saúde do Trabalhador, 1., 2009 - Avaliação da Rede Nacional de Atenção Integral em Saúde do Trabalhador
2008-2009. Brasília: Ministério da Saúde; Fiocruz; UFBA, 2011. Disponível em: < http://portal.saude.gov. br/portal/arquivos/pdf/inventario_renast.pdf $>$. Acesso em: 4 out. 2013.

MENDES, R.; DIAS, E. C. Da medicina do trabalho à saúde do trabalhador. Revista de Saúde Pública, São Paulo, v. 25, n. 5, p. 341-349, 1991.

ORGANIZACION MUNDIAL DE LA SALUD. Salud de los trabajadores: plan de acción mundial. Ginebra: OMS, 23 maio 2007. 60 Asamblea Mundial de la Salud. Punto 12.13 del orden del dia. Documento OMS WHA60.26. Disponível em: < http://apps.who.int/gb/ ebwha/pdf_files/WHA60/A60_R26-sp.pdf > . Acesso em: 29 nov. 2013.

Salud de los trabajadores: plan de acción mundial, In: ASAMBLEA MUNDIAL DE LA SALUD, 60., Ginebra, 2006. Ginebra: OMS, 2007. 12 p.

RIO GRANDE DO SUL (Estado). Convênio entre o Estado do Rio Grande do Sul por intermédio da Secretaria da Saúde e o Município de Alegrete objetivando a implementação do Centro de Referência Regional de Saúde do Trabalhador. Diário Oficial [do] Estado do Rio Grande do Sul, Porto Alegre, RS, 28 dez. 2000a. Atos da Secretaria de Saúde, p. 55.

. Decreto $\mathrm{n}^{\mathrm{o}}$ 40.222, de 02 de agosto de 2000 . Institui o Sistema de Informações em Saúde do Trabalhador, e dá outras providências. Diário Oficial [do] Estado do Rio Grande do Sul, Porto Alegre, RS, 02 ago. 2000b. Atos do Governador, p. 1.

. Secretaria da Saúde. Centro Estadual de Vigilância em Saúde (CEVS). Ata do encontro dos CEREST do Rio Grande do Sul, 14 de agosto de 2009. Porto Alegre: CEVS, 2009a. 5 p.

. Divisão de Vigilância em Saúde do Trabalhador. Portaria $\mathrm{n}^{\mathrm{o}}$ 70, de 18 de dezembro de 2003. Dispõe sobre a implementação dos CEREST, no Estado do Rio Grande do Sul. Diário Oficial [do] Estado do Rio Grande do Sul, Porto Alegre, RS, 08 jan. 2004. Atos da Secretaria de Saúde, p. 49-50.

- Pacto pela Saúde 2008 para o Rio Grande do Sul - Indicadores de Pactuação Estadual. Disponível em: <http://www1.saude.rs.gov.br/ dados/1305311917615Argumentos\%20para\%20 inclus\%E3o\%20dos\%20Indicadores\%20RS.pdf > . Acesso em: 4 out. 2013.

Plano Estadual de Saúde do Trabalhador 2002. Disponível em: < http://www.corag.com.br/index. php?option $=$ com_jornal\&pagina $=065 \&$ tipo $=$ pdf\&jorn $\mathrm{al}=$ doe $\&$ data $=2002-12-13 \&$ view $=$ pagina $>$. Acesso em: 6 ago. 2009.

. Sistema de Informações em Saúde do Trabalhador (SIST). Disponível em: < http://www.sist. saude.rs.gov.br/ist/index.jsp>. Acesso em: 22 jun. 2009b. 
SOUZA, R. R. A regionalização no contexto atual das políticas de saúde. Ciência \& Saúde Coletiva, Rio de Janeiro, v. 6, n. 2, p. 451-455, 2001.

STATACORP LP. Stata Statistical Software: release 10, College Station, Texas: StataCorp LP: 2005.

VASCONCELLOS, L. C. F; RIBEIRO, F. S. N.

Investigação epidemiológica e intervenção sanitária em saúde do trabalhador: o planejamento segundo bases operacionais. Cadernos de Saúde Pública, Rio de Janeiro, v. 13, n. 2, p. 269-275, 1997.

WÜNSCH FILHO, V. Perfil Epidemiológico dos Trabalhadores. Revista Brasileira de Medicina do Trabalho, Belo Horizonte, v. 2, n. 2, p. 103-117, 2004. Variações e tendências na morbimortalidade dos trabalhadores. In: MONTEIRO, C. A. Velhos e novos males da saúde no Brasil: a evolução do país e de suas doenças. 2. ed. São Paulo: Hucitec, 2000. p. 289-330. 